\title{
A Study of Using Smart Book to Enhance Communication Ability for Hearing-Impaired Students
}

\author{
https://doi.org/10.3991/ijet.v13i12.8812 \\ Kemmanat Mingsiritham $(\bowtie)$ Gan Chanyawudhiwan \\ Sukhothai Thammathirat Open University, Nonthaburi, Thailand \\ kemmanat.min@hotmail.com
}

\begin{abstract}
The research aimed to study the use of smart book to enhance communication ability and satisfaction of hearing-impaired students. The content for the research composed of three aspects; 1) travelling by BTS, 2) getting a personal identification (ID), and 3) accessing health care service. The samples were 10 hearing-impaired high school students derived from purposive sampling. The research instruments were smart book, evaluation form of communication ability and questionnaire of satisfaction. The data was statistically analyzed by mean, standard deviation, and content analysis. The research findings were as follow: 1) The evaluation on communication ability found that the students gained the communication ability at the level of "good", $(\bar{X}=2.84$, S.D. $=.37)$ considering on any item, the students was able to communicate with others with most frequency $(\overline{\mathrm{X}}=3.00$, S.D. $=0.00)$, the less was that the students were able to choose the content for communication $(\bar{X}=2.90$, S.D. $=0.32)$, and the students were able to apply in real situation, and applied the use of application to others. $(\bar{X}=2.80$, S.D. $=0.42)$ and 2$)$ The evaluation on satisfaction of the students to the smart book found that the quality of smart book was at the level of "most", $(\bar{X}=4.52$, S.D. $=.58)$ considering on any item, the application for communication ability was valuable for use with the most average $(\bar{X}=4.90$, S.D. $=0.32)$, the less was that the application was able to search for keywords conveniently and fast $(\bar{X}=4.80$, S.D. $=0.42)$, and the clarification of using sign language for explaining the content respectively. $(\bar{X}=4.70$, S.D. $=0.48)$
\end{abstract}

Keywords - Smart book, Application, Communication ability, Hearing-impaired students

\section{Introduction}

A special education for handicaps is a policy of human resource development of the country. Handicaps who were developed the life quality will be sufficient and benefits the society [1], and access to the right equally in society and get rid of the discrimination to handicaps including for supporting and increase the opportunity for handicaps to gain the educational service in society. [2].

In knowledge-based society, media and technology are used for learning management and increase the learning efficiency and quality. Most handicaps were neglected 
to have opportunity for studying so the media and technology for handicaps learning is a must to provide for learning management. [3]. Instructional media is the important factor to help the hearing-impaired students to receive the information and communicate in social. Technological media is well known and popular in social for all even sex, age and level of study. Technological media becomes the media for learning development, communication, and makes understanding for message senders and receivers. Technological media has changed and adapted to be interesting, modernized, and up to date. However, the instructional media for handicaps are not enough for handicaps in society. Hearing-impaired students need the instructional media to facilitate and support the hearing perception instead of the hearing-impaired condition. The rapid growth of technology effect the application for communication by research and develop the modernized instrument displayed in multimedia will enable learning achievement for the handicaps. The pictures and texts and daily situations in multimedia that is according to the hearing-impaired students' need effect the success of learning management. The hearing-impaired students will understand and know concretely. The communication to others in social will be accurate and gain the effective communication for the future human life. It is also to help the extension the opportunity of hearing-impaired students and equality in society. The researcher had the idea to create smart book for the hearing-impaired students using Android operation system on mobile phone. The information was stored in database and easy for access both in the application database and other supporting information database. The application had helper for right pronouncing the phrase or words, sentences with others. The application is a tool for hearing-impaired students to use knowledge in daily life and be able to develop the potential for studying and live happily in social.

\section{Review of the Literature}

The way of communication for hearing-impaired person was to use sign language. The application of instructional method and media for communication was done for helping the hearing-impaired person but there was still a problem for hearing-impaired person. The most of perception was to use eye in sign language communication. The limitation in Thai language and standard of Thai sign language is existed. The hearingimpaired students have problem in Thai language use. The knowledge of Thai words and word order are still being a problem in communication, so eye perception is very important for doing activities in daily life. [4] Learning need to use eye but for hearingimpaired students use listening instead of watching by eye for communication which leads to learning and thinking. Comparing the similarity, diversity, association, or forecasting can be practiced.

Media design for hearing-impaired students should be multimedia. Only text in the media is not enough for understanding. [5] The multimedia might be texts, pictures, and sign language to make better understanding than using only texts or texts and sign language. The media used texts and pictures are better than the media use only texts or texts and sign language. So, the multimedia design for hearing-impaired students was used. 1) Sign language translator and oral interpreters. Those translators help people to 
communicate with the hearing-impaired students in any situation. In the multimedia, the translator should be at same position. 2) Sub-title to show texts related to the content. The sub-title acts same as the language translator immediately, 3) the illustration to support the texts or content in the multimedia. The audiences who not get familiar with sign language will get better understanding the content if the multimedia compose of pictures or animation.

\section{Research Methodology}

\subsection{A design of smart book}

Smart book was designed and developed to smart book application used on mobile phone with Android Operating System and access at STOP smartbook application. This application used animation, social media, sign language to search for situation need individually. The design focused on easy using and the administrator for the application can improve the application whereas there is no impact for users. The functions of Smart Book Application were shown in figure 1-3.
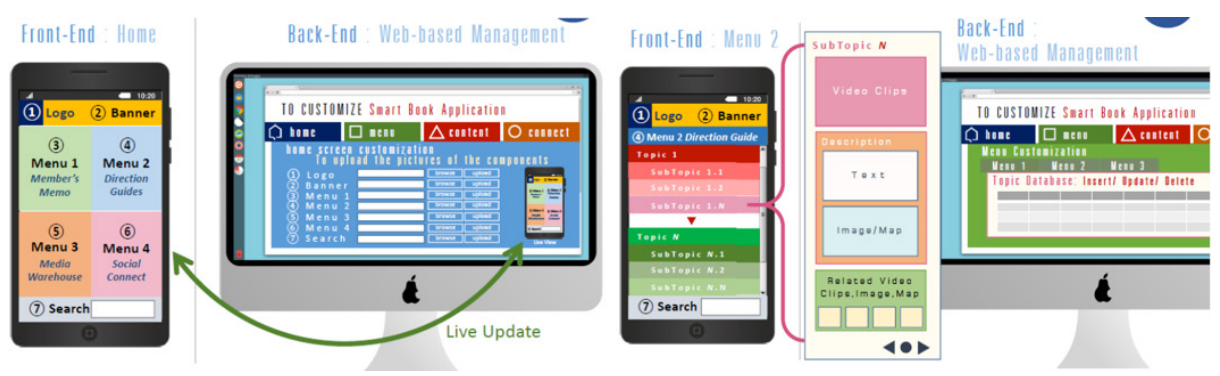

Fig. 1. Function of main menu of Smart Book Application
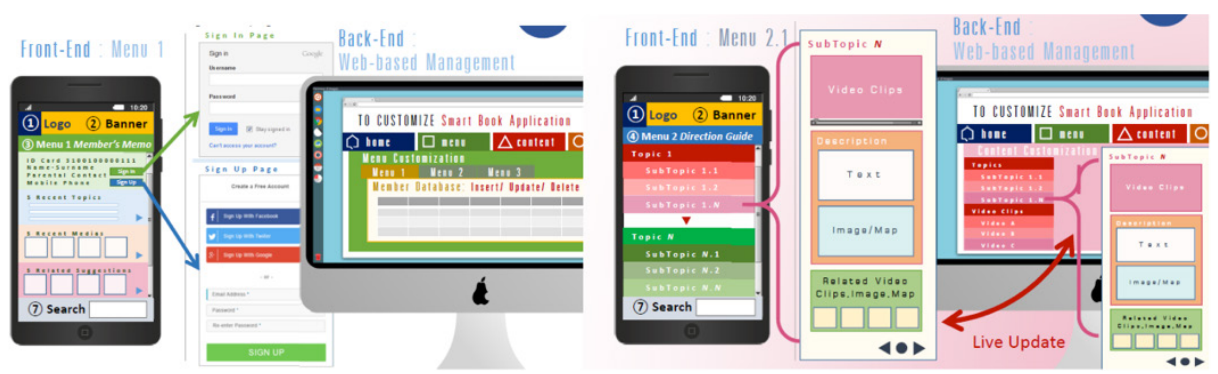

Fig. 2. Management system and functions of media in Smart Book Application 


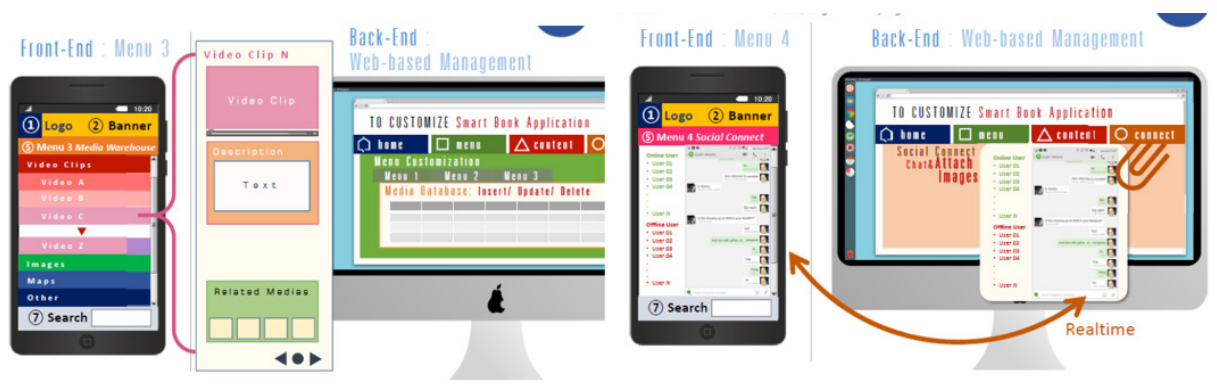

Fig. 3. Display of Smart Book Application

\subsection{Samples}

The samples were 10 hearing-impaired high school students derived from purposive sampling.

\subsection{Research instruments}

The research instruments were (1) Evaluation form of communication ability, using rating scale and rubric scoring. The researcher used evaluation form of communication ability during the experiment of using smart book, (2) Questionnaire for satisfaction to smart book, using 5 rating scale; most, much, average, little, and least. The questionnaire consisted of personal data of the samples, the appropriateness on content designed, media, adoption, obstacles and suggestion. The questionnaire included openended for interviewing the experimental group and followers.

\subsection{Data Collection}

The researcher implemented the smart book as the following steps;

\section{Plan before the implementation}

1. Prepare the auditorium for explaining the experiment to the experimental group of students.

2. Prepared the instruments for collection data for example, Application of smart book, evaluation form of communication ability, and questionnaire of satisfaction.

\section{The experiment of using application of smart book}

1. The experimental group of students were trained to use the smart book application on mobile phone with Android OS and sign language translator.

2. The experimental group of students learned to use smart book application individually with advise from lecturer.

3. After the learning activity of training in the class, the research explained how to use smart book in real situation and follow up the evaluation of communication ability in real situation. 
4. The experimental group of students used the smart book application in real situation, the lecturer follow up and evaluated the communication ability in real situation.

5. The experimental group of students evaluated the satisfaction to the smart book application and interviewed the samples and followers.

\section{$4 \quad$ Research Findings}

The researcher used smart book application with 10 samples, evaluated the communication ability in 3 real situations; 1) Travelling by BTS, 2) Getting a personal identification (ID), and 3) Accessing health care service as shown in figure 4-6.
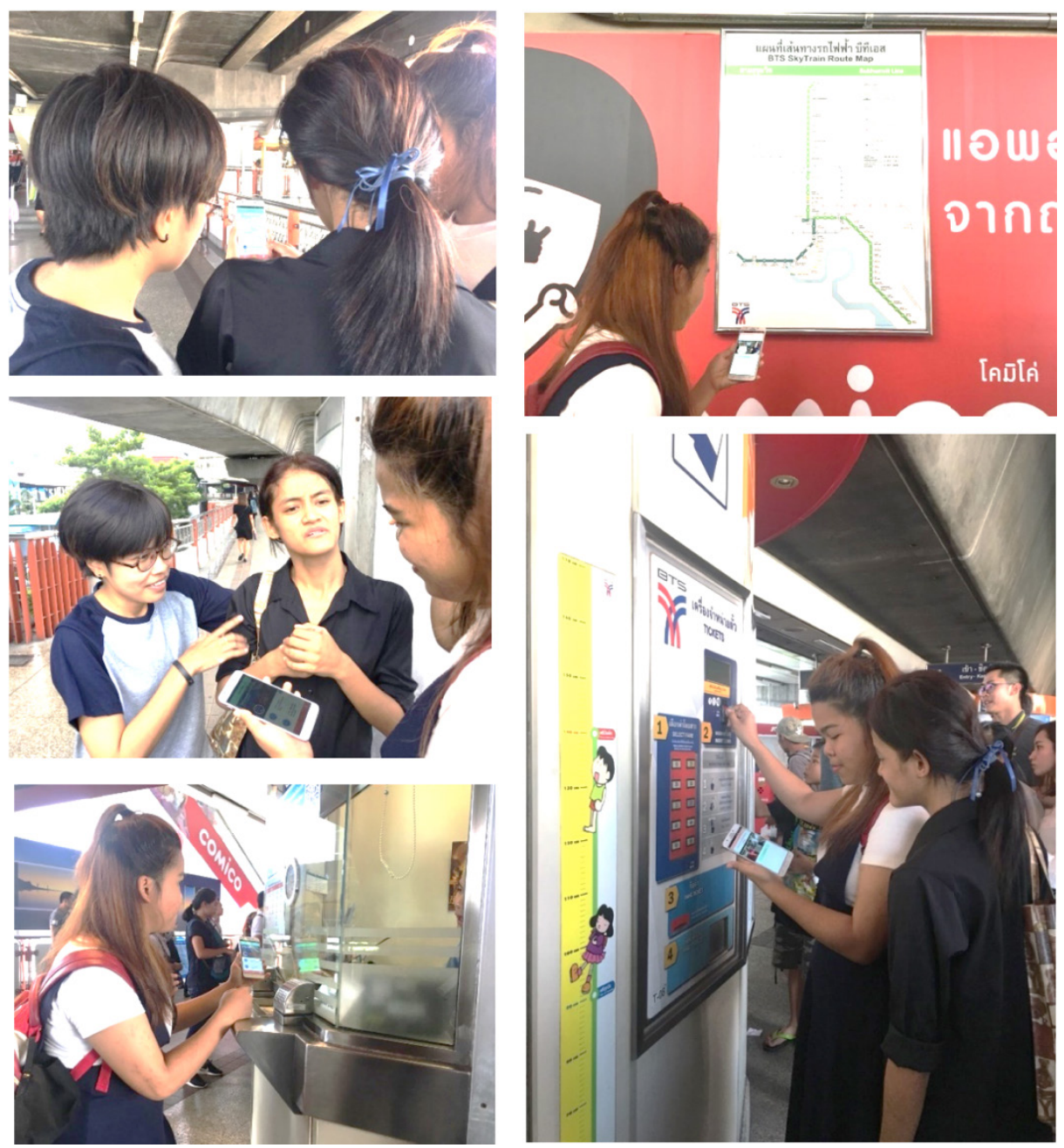

Fig. 4. The use of smart book for travelling by BTS 
Paper-A Study of Using Smart Book to Enhance Communication Ability for Hearing-Impaired Students
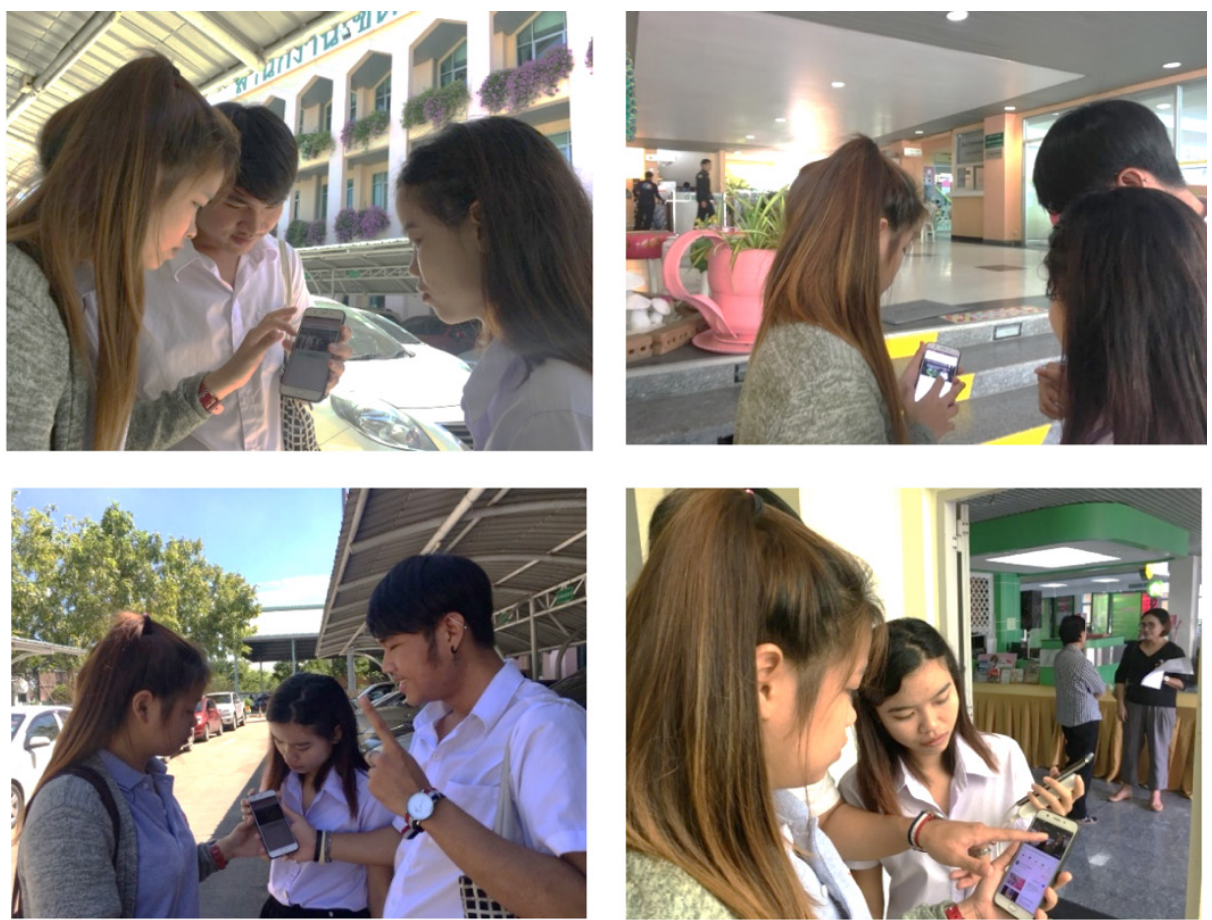

Fig. 5. The use of smart book for getting identification card
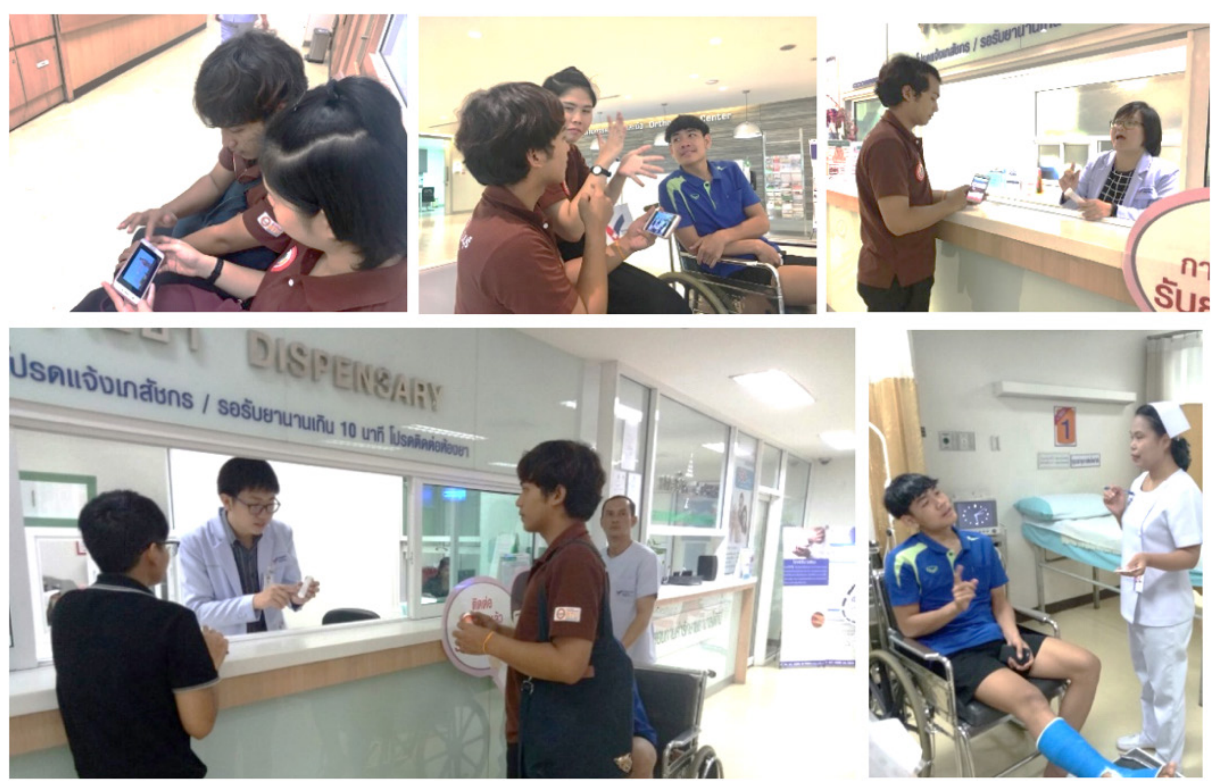

Fig. 6. the use of smart book in accessing health care service 
The evaluation on communication ability found that the communication ability of the hearing-impaired students was at the level of "good" ( $\overline{\mathrm{X}}=2.84$, S.D. $=.37)$, considering in any item, the ability to communicate with other related people was the most $(\overline{\mathrm{X}}=3.00$, S.D. $=0.00)$ the less was the ability to select content for communication $(\overline{\mathrm{X}}=$ 2.90 , S.D. $=0.32)$ and the ability to use in real situation and the ability to use application with others $(\overline{\mathrm{X}}=2.80$, S.D. $=0.42)$ as shown in table 1 .

Table 1. the evaluation on communication ability $(\mathrm{N}=10)$

\begin{tabular}{|l|c|c|c|}
\hline \multicolumn{1}{|c|}{ Description } & $\bar{X}$ & S.D. & meaning \\
\hline Ability to access the application & 2.70 & 0.48 & good \\
\hline Ability to select the content for communication & 2.90 & 0.32 & Good \\
\hline Ability to use in real situation & 2.80 & 0.42 & good \\
\hline Ability to communicate with other related people & 3.00 & 0.00 & Good \\
\hline Ability to advise the application for the others & 2.80 & 0.42 & good \\
\hline \multicolumn{1}{|c|}{ Average } & $\mathbf{2 . 8 4}$ & $\mathbf{0 . 3 7}$ & good \\
\hline
\end{tabular}

The result on implementation of smart book found that in the real situation of group such as travelling by BTS which the communication helps each other, some people who never travelled by BTS had no confidence to communicate with the officer. Travelling by group helped them have more confidence. The small fonts of sub-title in the media caused the samples could not read. So, the researcher had improved by extending the fonts' size and used the fonts that were easy to read.

The researcher implemented the smart book in the laboratory with the help of lecturer and the sign language translator. After the real situation, the samples were evaluated the satisfaction to the smart book. The evaluation on satisfaction found that the satisfaction was at the level of "most", $(\bar{X}=4.52$, S.D. $=.58)$ considering by the item, the most average was that the smart book application for communication was valuable for use $(\overline{\mathrm{X}}=4.90$, S.D. $=0.32)$, the less was that the smart book application could search the information by keywords conveniently and rapidly, $(\bar{X}=4.80$, S.D. $=0.42)$ and the clarity of sign language for describing the content respectively. $(\bar{X}=4.70$, S.D. $=0.48)$ as shown in table 2 .

Table 2. the satisfaction to smart book $(n=10)$

\begin{tabular}{|l|c|c|c|}
\hline \multicolumn{1}{|c|}{ Description } & $\bar{X}$ & S.D. & meaning \\
\hline $\begin{array}{l}\text { 1. The smart book application can help for more convenient communication. } \\
\text { 2. The smart book application is convenient for use in real situation. }\end{array}$ & 4.40 & 0.52 & Much \\
\hline $\begin{array}{l}\text { 3. The smart book application is designed appropriately (picture, text, color, icon, } \\
\text { button, link). }\end{array}$ & 4.40 & 0.52 & Much \\
\hline $\begin{array}{l}\text { 4. The smart book application can search the information by keywords conve- } \\
\text { niently and rapidly. }\end{array}$ & 4.80 & 0.52 & Most \\
\hline $\begin{array}{l}\text { 5. The clarity of sign language for describing the content. } \\
\text { 6. The continuality of content delivering. }\end{array}$ & 4.70 & 0.48 & Most \\
\hline
\end{tabular}




\begin{tabular}{|l|c|c|c|}
\hline \multicolumn{1}{|c|}{ Description } & $\bar{X}$ & S.D. & meaning \\
\hline 7. The smart book application for communication is valuable for use. & 4.90 & 0.32 & Most \\
\hline 8. The problem during smart book application ca be solved. & 4.20 & 0.63 & Much \\
\hline 9. The smart book application for communication satisfied you. & 4.30 & 0.48 & Much \\
\hline 10. The smart book application is introduced to the others. & 4.50 & 0.71 & Most \\
\hline \multicolumn{1}{|c|}{ Average } & $\mathbf{4 . 5 2}$ & $\mathbf{0 . 5 8}$ & Most \\
\hline
\end{tabular}

The interview of hearing-impaired students on the use of smart book application, the content analysis was found as follow:

The samples agreed that the smart book application can use for communication, easy to use, suit to use for warning/notice of the transportation and use by mobile phone conveniently. These are the result from interviewing:

"Feel good with easy using smart book application. It helped for me a better communication"

"Help for good communication, easy use. Click application, the menu comes"

"Easy understanding, not too long. It helps me lots for communication"

"Smart app, easy to use for communication, I need more sign language"

The interview of followers found that they tried to use other method to help the hearing-impaired students who were broken in hearing to get benefit from smart book application. The application response and solve the problem of communication and decrease time and steps in communication. There were relation of the contents and easy understanding. The hearing -impaired students can increase their potential to communicate and spent daily life happily in social. The example of interviewing:

"The application is benefit for hearing-impaired students. The students can learn from mobile phone. The content is easy for understanding, communication and travel in the correct way"

"The smart book application is very useful for the hearing-impaired student for communication, but the warning should be provided for safety"

"The contents have related each other. The application helps more convenient, decrease time to contact with the organization"

\section{$5 \quad$ Discussion and Conclusion}

The design of smart book for hearing-impaired students was the application used on mobile phone which was the technological tool of people at present. Mobile phone can support the application for people in daily life according to the way of life. This technological tool is necessary for daily life and harmonized to the communication behaviour of hearing-impaired students and normal people which is different in reading, writing with concise and easy understanding. The design of smart book was related to the communication behavior. The content is easy to understand and incomplex to help hearing-impaired person have confidence to communicate with others. The hearing- 
impaired person likely communicated to the hearing-impaired person, not with normal person. The important reason was the structure of language use for communication of hearing-impaired person was different from normal people language or the Thai structure. So, the hearing-impaired person was lack of confidence to communicate with normal people. [6] So, the communication by mobile phone was the tool of hearing-impaired person in searching information. Moreover, the content is important for the hearing-impaired person to use for communication with others. The classification of content in categories made the content concise and the pictures also made easier understanding concretely. [7].

In addition, the design of smart book for hearing-impaired students had used the simply texts and pictures instead of lecturing and used texts intermittently for easy understanding. The sign language was translated by the skillful sign language translator. The media production for hearing-impaired students using the pictures and simple graphics, sun-content related to main content, all made learners remembered the content more. [8] The skillful sign language translator also helped for media production of hearing-impaired students that could not communicate by reading or writing completely. [9] In addition, the media production for hearing-impaired students used multimedia such as video, sign language pictures and texts.

\section{Acknowledgment}

This research was supported a budget for development of distance education media from Research and Development Research Institute, Sukhothai Thammathirat Open University.

\section{$7 \quad$ References}

[1] Division of Media Production for Handicaps. (2550). Problems and needs of media using of teachers and hearing-impaired students in the Secondary School for the Deaf. Bangkok: Educational Technology Centre, Office of Non-formal Education Administration, Office of the Permanent Secretary, Ministry of Education.

[2] Ministry of Education. (2014). Association for Basic Education Curriculum Development. retrieved from http://www.thaigov.go.th/th/news-ministry

[3] Malee Thepmuang. (2008). Computer assisted Instruction for Hearing-impaired Students in Mathematics, Case study: Uthai Thani Special Education Centre. (Thesis for a master's degree in Education, Information Technology) King Mongkut's University of Technology, North Bangkok, Bangkok.

[4] Padoong Arayawinyu. (1999). Inclusive Education of Normal Students and Special Needs Students. Bangkok: Waan Kaew Press.

[5] Jitprapa Sri-on et. Al., (2001). nVideo Media Production for Hearing-Impaired Students on Computer Teching for Hearing-Impaired Person. Research Report of Ratchasuda College, Mahidol University, Nakhon Pathom.

[6] Supaporn Kakaew. (2010). Quality of Information on Website of Regional Special Education Centre in Thailand. (Thesis for a master's degree in Educational Administration). Sukhothai Thammathirat Open University, Nonthaburi. 
[7] Methinee Suprapas. (2008). Computer Assisted Instruction on Introduction to Sign Language for Hearing-impaired Students (Thesis for a master's degree in Vocational Education Technology and Technical Education) King Mongkut's University of Technology, Ladkrabang, Bangkok.

[8] Pawinee Pawanuntapoot. (2011). A multimedia package design to develop ready madejewelry pave setting skills for people with hearing impairment (Thesis for a master's degree in Technical Education Technology) King Mongkut's University of Technology, North Bangkok, Bangkok.

[9] Kemmanat Mingsiritham and Gan Chanyawudhiwan . (2017). A Development of Smart Book to Assist Communication for Hearing Impaired Students. International (Humanities, Social Sciences and Arts) Volume 10 Number 5 July - December 2017, 98-11.

\section{Authors}

Kemmanat Mingsiritham is an Associate Professor at the Office of Educational Technology, Sukhothai Thammathirat Open University, Nonthaburi 11120 Thailand. Her research interests include Virtual Learning Environment, e-Learning, and Distance Learning. (kemmanat.min@hotmail.com)

Gan Chanyawudhiwan is an Instructor at the Office of Educational Technology, Sukhothai Thammathirat Open University, Nonthaburi 11120 Thailand. Her research interests include Virtual Learning Environment, e-Learning, and Distance Learning. (ganechay@gmail.com)

Article submitted 28 April 2018. Resubmitted 10 June 2018. Final acceptance 11 June 2018. Final version published as submitted by the authors. 